\title{
Attitudes of members of the Wroclaw Division of the Polish Cardiac Society to the European Society of Cardiology Guidelines: Survey study
}

\author{
Szymon Urban ${ }^{1}$, Mikołaj Błaziak¹, Maksym Jura², Jan Biegus', Wiktor Kuliczkowski', Robert Zymliński \\ 'Department of Heart Diseases, Wroclaw Medical University, Wrocław, Poland \\ ${ }^{2}$ Student Scientific Organization, Institute of Heart Diseases, Wroclaw Medical University, Wrocław, Poland
}

\author{
Correspondence to: \\ Szymon Urban, MD \\ Department of Heart Diseases, \\ Wroclaw Medical University, \\ Borowska 213, 50-556 Wrocław, \\ Poland, \\ phone: +486964890 58, \\ e-mail: \\ szymon.urban.wro@gmail.com \\ Copyright by the Author(s), 2022 \\ DOI: 10.33963/KP.a2021.0150 \\ Received: \\ September 20, 2021 \\ Accepted: \\ November 2, 2021 \\ Early publication date: \\ November 3, 2021
}

\section{INTRODUCTION}

Clinical guidelines are recommendations concerning clinical pathways. Their development involves analysis of evidence-based data and incorporation of the different quality of evidence. Guidelines aim to improve the quality of care, patient prognosis [1], and cost-effectiveness [2]. Such documents are useful for physicians who perceive them as a structured source of advice and valuable educational tools. On the other hand, the most common complaints are that guidelines are too simplified and unsuitable to be applied to individual patients or are too rigid. Moreover guidelines are accused of limiting the doctor's autonomy. Another plea is that guidelineses utility in small, peripheral hospitals is limited due to inaccesibility to sophisticated diagnostic and terapeutic methods [3-5]. Based on these perceptions, we conducted a pilot survey to evaluate the opinions and remarks of the members of the Wroclaw Division of the Polish Cardiac Society regarding the European Society of Cardiology (ESC) guidelines. The attitudes regarding cardiological guidelines were not assessed before. We believe that a better understanding of physicians' attitudes toward clinical guidelines and possible problems associated with them can improve their future construction and implementation.

\section{METHODS}

The survey was conducted among members of the Wroclaw Division of the Polish Cardiac Society, and questionnaires were distributed twice (May 28 and June 10, 2021) by e-mail. In total, messages were sent to 438 members of Wroclaw Division of Polish Cardiac Society.
Participants' data, including professional characteristics, were not collected to keep the study anonymous - however, most of respondents are cardiologists and internal medicine specialists employed both in hospitals and in outpatient clinics. We used Microsoft Office Forms to create the questions and Microsoft Excel to collect the data. The analysis, including percentage calculations, was performed automatically by Microsoft Forms infrastructure. No further statistical analysis was conducted. We prepared seven close-ended questions. For questions 1,2 , and 7 , we provided 2 answers, and for questions $3,5,6$, and 8 , we presented 3 answers. Moreover, we added the possibility to give individual responses for questions 7 and 8 . We also prepared 2 open-ended questions. The first requested to specify situations in which ESC guidelines have a real impact on treatment decisions for those who had chosen the answer "in some cases" for question 3. The second asked if there were any elements of the guidelines that needed further more detailed clarification.

The study was approved by the Board of the Wroclaw Division of the Polish Cardiac Society. The survey was distributed among the members of the Wroclaw Division of the Polish Cardiac Society via the Polish Cardiac Society mailing list. The survey was voluntary and anonymous, and no personal or restricted data were collected.

\section{RESULTS AND DISCUSSION}

In total, 101 responses were obtained, which constitutes $23 \%$ of distributed questionnaires. All respondents conceded that the ESC guidelines were valuable tools in daily cardio- 
1. Do you think that ESC guidelines are helpful during daily practice?

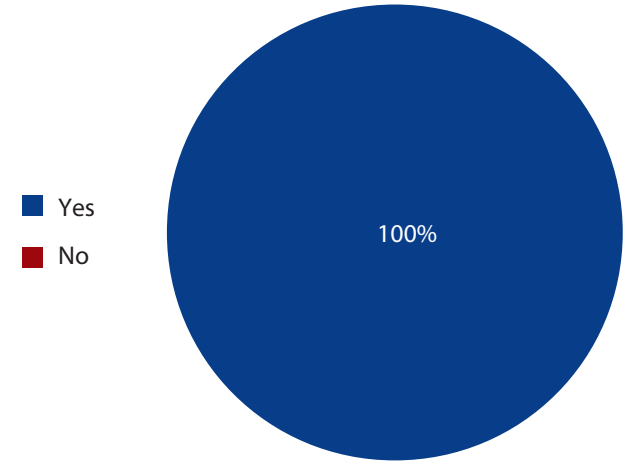

3. Do ESC guidelines have a real impact on your treatment decisions?

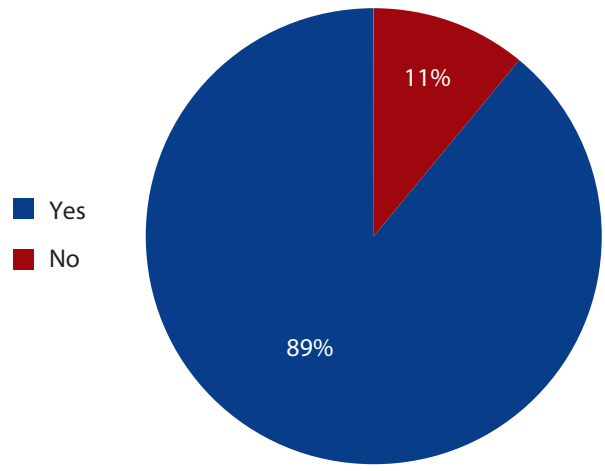

5. Which form of ESC guidelines do you prefer the most?

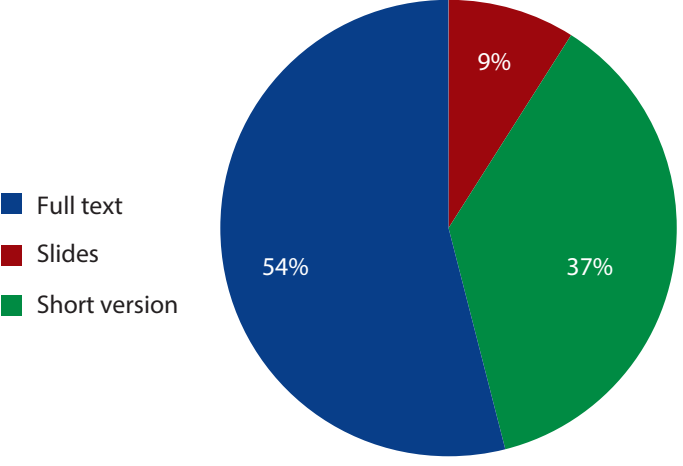

2. Do you think that ESC guidelines are presented in a sufficiently transparent manner?

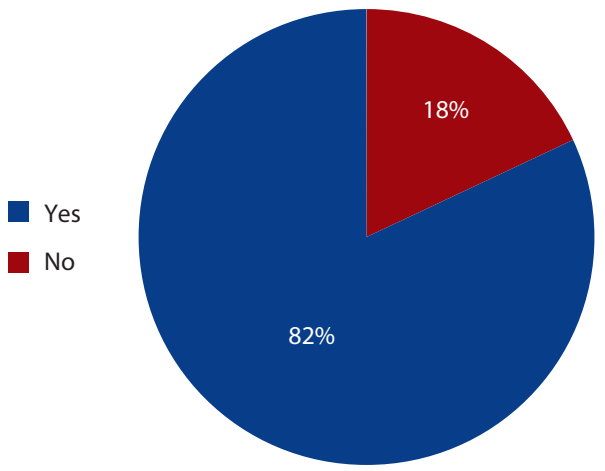

4. Do you refer to ESC guidelines during treatment implementation or while proposing a diagnostic pathway?

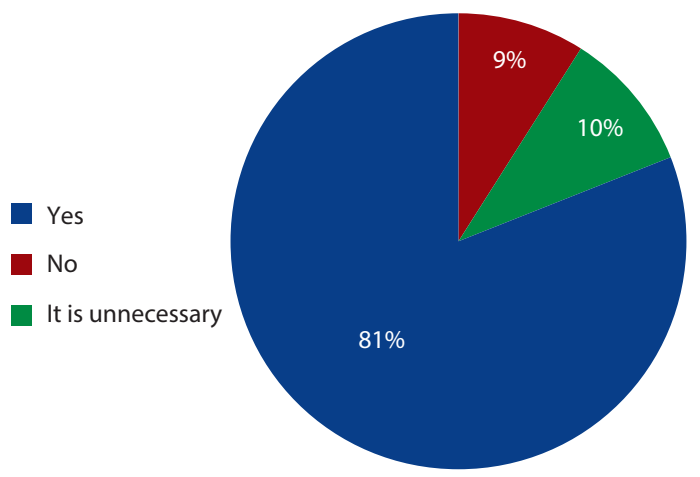

6. What are your concerns with the ESC guidelines?

Infrequent updates

Maladjustment to local conditions

Other

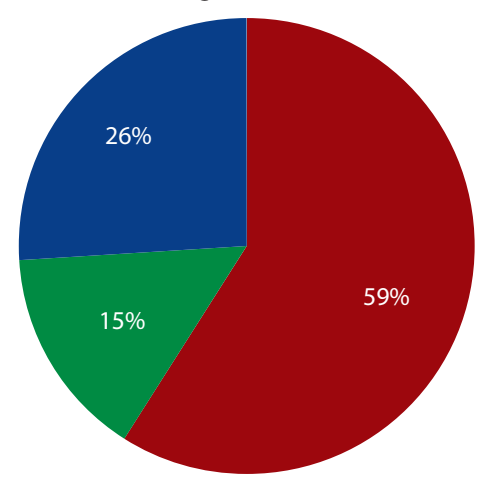

7. While reading ESC guidelines, you limit yourself to:

Reading only specified changes

analysing algorithms and tables

Reading full text

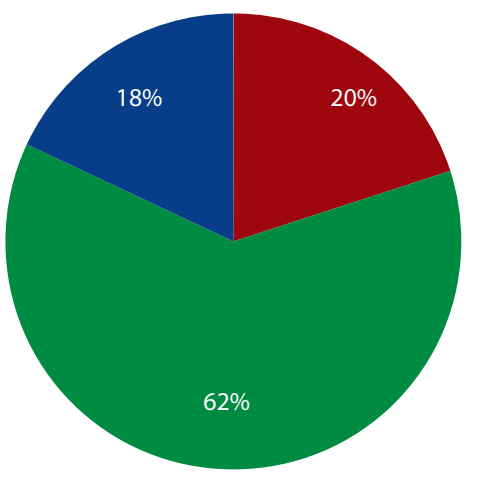

Figure 1. The percentage share of the responses to the seven close-ended questions. Responding to all questions was not compulsory Abbreviations: ESC, European Society of Cardiology 
logical practice, and $89 \%$ of the respondents admitted that the guidelines had a noticeable impact on their clinical decisions (Figure 1). This was a more favorable attitude than the ones reported by previous studies performed outside Poland $[4,6]$. Respondents who recognized the usefulness of the guidelines, particularly in specific cases, argued that they applied them only to severely ill patients. Further, $81 \%$ of the respondents referred to the guidelines to explain the implemented treatment to the patient. Regarding the clinicians' attitudes toward the guidelines, $62 \%$ of the respondents declared that they read the full text of the new directives, but only $54 \%$ found an optimal method for getting acquainted with them. Almost $40 \%$ of the respondents reported only checking the new algorithm presented in figures or changes in the recommendations in tables presented at the beginning of the text. Significantly, more than half of the respondents' critical remarks focused on the disparity between guidelines and regional possibilities, which raised the issue of reimbursement and inaccessibility of some diagnostic and therapeutic methods. Similarly, in other studies, cost issues were the most often mentioned obstacles to guideline implementation [7]. Approximately a quarter of the respondents thought that updates were published too infrequently. Another common complaint was that guidelines needed to place further emphasis on an interdisciplinary approach. Inapplicability of recommendations to multimorbid populations was regarded as an important barrier in their implementation, which has also been revealed in several previous studies $[4,8]$. Some respondents felt that information about drug interactions and their impact on non-cardiac diseases was missing. Moreover, respondents reported that guidelines needed to be presented in a more readable manner and should include more references to practice and deviations from their application. Similarly, other studies argued that the guideline format was an important factor in shaping physicians' attitudes [8]. Some respondents suggested including a patient leaflet in the guidelines, which was also mentioned by Carlsen et al. [8].

Notwithstanding the generally favorable and positive attitude of the physicians toward the guidelines, their implementation can be suboptimal $[9,10]$. A recent study regarding 460 patients with coronary artery disease revealed that therapeutic goals of body mass index, glycated hemoglobin, low-density lipoprotein cholesterol, systolic blood pressure, and physical activity are not commonly achieved. Furthermore, none of the examined patients achieved all the main prevention goals [10]. Proper guideline adherence is essential as it is associated with a better prognosis [11]. Barriers that can hinder guideline adherence vary. Cabana et al. [12] differentiated three categories, such as knowledge, attitude, and behavior, and indicated that barriers were dependent on local settings and specific conditions. Indeed, over half of our participants (59\%) pointed out that guidelines were not adjusted for regional variability.
Our study has several limitations. First, our results may not reflect the actual attitude of Polish cardiologists to the ESC guidelines due to the limited number of responses and the area of the study being restricted to one voivodship. Furthermore, due to the online dissemination of the survey, we can assume that it was filled mostly by those doctors accustomed to using e-mail on a daily basis. Finally, the survey was based on closed questions, which limited the possibility of expressing complex opinions.

In conclusion, guidelines are mostly appreciated by the participants. They are seen as helpful tools in daily practice and as a source of information that provides ways to reason with patients. One crucial concern, which is an essential practical conclusion of this study and should be addressed in future guideline construction, is the incompatibility of guidelines with the local conditions such as limitations related to reimbursement or the dependence of guidelines on overly sophisticated diagnostic or therapeutic methods. Undoubtedly one of the important finding identified in the survey is the invaluable role of the guidelines in the more severe, difficult clinical cases.

\section{Article information}

Acknowledgments: This work was supported by the Department of Heart Diseases, Wroclaw Medical University, and the Wroclaw Division of the Polish Cardiac Society.

Conflict of interest: None declared.

Open access: This article is available in open access under Creative Common Attribution-Non-Commercial-No Derivatives 4.0 International (CC BY-NC-ND 4.0) license, allowing to download articles and share them with others as long as they credit the authors and the publisher, but without permission to change them in any way or use them commercially. For commercial use, please contact the journal office at kardiologiapolska@ptkardio.pl.

\section{REFERENCES}

1. Grimshaw JM, Russell IT. Effect of clinical guidelines on medical practice: a systematic review of rigorous evaluations. Lancet. 1993; 342(8883): 1317-1322, doi: 10.1016/0140-6736(93)92244-n, indexed in Pubmed: 7901634.

2. Rotter T, Kinsman L, James E, et al. Clinical pathways: effects on professional practice, patient outcomes, length of stay and hospital costs. Cochrane Database Syst Rev. 2010(3):CD006632, doi: 10.1002/14651858.CD006632. pub2, indexed in Pubmed: 20238347.

3. Graham ID, Brouwers M, Davies C, et al. Ontario doctors' attitudes toward and use of clinical practice guidelines in oncology. J Eval Clin Pract. 2007; 13(4): 607-615, doi: 10.1111/j.1365-2753.2006.00670.x, indexed in Pubmed: 17683303.

4. Birrenbach T, Kraehenmann S, Perrig M, et al. Physicians' attitudes toward, use of, and perceived barriers to clinical guidelines: a survey among Swiss physicians. Adv Med Educ Pract. 2016; 7: 673-680, doi: 10.2147/AMEP. S115149, indexed in Pubmed: 28008300.

5. Solà I, Carrasco JM, Díaz Del Campo P, et al. Attitudes and perceptions about clinical guidelines: a qualitative study with Spanish physicians. PLoS One. 2014; 9(2): e86065, doi: 10.1371/journal.pone.0086065, indexed in Pubmed: 24505253.

6. Tunis SR, Hayward RS, Wilson MC, et al. Internists' attitudes about clinical practice guidelines. Ann Intern Med. 1994; 120(11): 956-963, doi: 10.7326/0003-4819-120-11-199406010-00008, indexed in Pubmed: 8172440.

7. Baiardini I, Braido F, Bonini $M$, et al. Why do doctors and patients not follow guidelines? Curr Opin Allergy Clin Immunol. 2009; 9(3): 228-233, doi: 10.1097/aci.0b013e32832b4651, indexed in Pubmed: 19390434. 
8. Carlsen B, Glenton C, Pope C. Thou shalt versus thou shalt not: a meta-synthesis of GPs' attitudes to clinical practice guidelines. Br J Gen Pract. 2007; 57(545): 971-978, doi: 10.3399/096016407782604820, indexed in Pubmed: 18252073.

9. Komajda M, Anker SD, Cowie MR, et al. QUALIFY Investigators. Physicians' adherence to guideline-recommended medications in heart failure with reduced ejection fraction: data from the QUALIFY global survey. Eur J Heart Fail. 2016; 18(5): 514-522, doi: 10.1002/ejhf.510, indexed in Pubmed: 27095461.

10. Krawczyk-Ożóg A, Płotek A, Hołda M, et al. Assessment of the implementation level of the guidelines for secondary prevention of cardiovascular disease in everyday clinical practice. Kardiol Pol. 2021; 79(4):434-441, doi: 10.33963/KP.15856, indexed in Pubmed: 33687867.

11. Komajda M, Cowie MR, Tavazzi L, et al. Physicians' guideline adherence is associated with better prognosis in outpatients with heart failure with reduced ejection fraction: the QUALIFY international registry. Eur J Heart Fail. 2017; 19(11): 1414-1423, doi: 10.1002/ejhf.887, indexed in Pubmed: 28463464

12. Cabana MD, Rand CS, Powe NR, et al. Why don't physicians follow clinical practice guidelines? A framework for improvement. JAMA. 1999; 282(15): 1458-1465, doi: 10.1001/jama.282.15.1458, indexed in Pubmed: 10535437. 